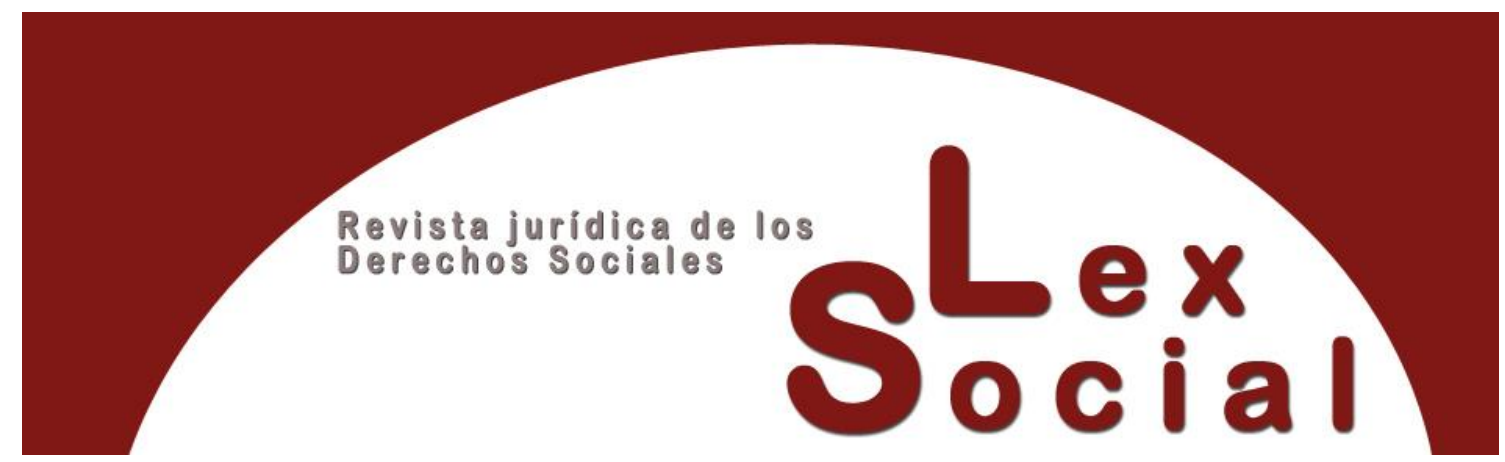

\title{
PANDEMIA, PERSONAL SANITARIO Y BURNOUT: EL SÍNDROME DE ESTAR QUEMADO COMO ENFERMEDAD DEL TRABAJO
}

\section{THE PANDEMIC, HEALTHCARE PERSONNEL AND BURNOUT: BURNOUT AS A WORK-RELATED DISEASE}

GUILLERMO GARCÍA GONZÁLEZ Profesor Titular de Derecho del Trabajo y de la Seguridad Social

Universidad Internacional de La Rioja https://orcid.org/0000-0002-5927-4124

Cómo citar este trabajo: García González, G. (2021). Pandemia, personal sanitario y burnout: el síndrome de estar quemado como enfermedad del trabajo. Lex Social: Revista De Derechos Sociales, 11 (2), 3-27. https://doi.org/10.46661/lexsocial.6001

\section{RESUMEN}

El burnout o síndrome de estar quemado se presenta en la actualidad como uno de los trastornos psicosociales de mayor trascendencia. La relevancia del burnout es especialmente significativa en las profesiones asistenciales, teniendo una singular repercusión en las ocupaciones del ámbito sanitario. A los tradicionales factores organizacionales que concurren en dicho ámbito, se unen en el contexto actual los elementos estresores derivados de la pandemia del covid-19, como el exceso de trabajo, la inseguridad en el desempeño de la profesión o la deficiencia de medios para desarrollar el trabajo. El presente artículo tiene como objetivo fundamental analizar la consideración del burnout como accidente de trabajo, mediante su identificación como enfermedad del trabajo ex art. 156.2 e) LGSS, enfocando el examen en su proyección al ámbito sanitario en el actual contexto de pandemia.

\section{$(\mathrm{CC})$ BY-NC-SA}


Palabras Clave: accidente de trabajo, burnout, enfermedad del trabajo, personal sanitario, síndrome de estar quemado.

\begin{abstract}
Nowadays, burnout is one of the most important psychosocial disorders. The relevance of burnout is especially significant in welfare professions, with a singular impact on healthcare occupations. In the current context, the stressors derived from the covid-19 pandemic, such as overwork, insecurity in the performance of one's profession or the shortage of means to carry out one's job are added to the traditional organisational factors that co-occur in this field. The main aim of this article is to analyse the consideration of burnout as an occupational accident, through its identification as a work-related illness ex art. 156.2 e) LGSS, by focusing the examination on its impact on the healthcare sector in the current context of the pandemic.
\end{abstract}

KEYWORDS: occupational accident, burnout, work-related illness, healthcare personnel, burnout syndrome.

\title{
SUMARIO
}

\section{Introducción.}

II. La configuración jurídica del burnout a través de su integración jurisprudencial.

III. El personal sanitario como colectivo especialmente expuesto al burnout.

IV. El burnout y su calificación como contingencia profesional: consideraciones previas.

$V$. Los trastornos psicosociales como enfermedades del trabajo: elementos delimitadores.

VI. El burnout como enfermedad del trabajo: especial referencia al personal sanitario.

VII. A modo de conclusión.

Bibliografía

\section{Introducción}

En 2019 la OMS reconoció oficialmente al síndrome de estar quemado o burnout como una problemática o fenómeno asociado al trabajo, tras la revisión decimoprimera de la CIE que entrará en vigor el 1 de enero de 2022. El burnout, con el descriptor QD85, se incardina en el apartado 24, "Factores que influyen en el estado de salud o en el contacto con los servicios de salud", categoría que abarca razones por las que personas consultan a los servicios de salud, pero que no se consideran enfermedades o condiciones de salud en sentido estricto. 
De acuerdo con el CIE-11, el burnout "es un síndrome conceptualizado como el resultado del estrés laboral crónico que no ha sido gestionado adecuadamente. Se caracteriza por tres dimensiones: sentimientos de agotamiento o carencia de energía; elevado distanciamiento mental del trabajo o sentimientos de negativismo o cinismo relacionado con el trabajo; (y) eficacia profesional reducida"1.

Desde una perspectiva psicosocial, el burnout es entendido como una respuesta psicológica al estrés laboral crónico de carácter interpersonal y emocional, que aparece en los profesionales de las organizaciones de servicios que trabajan en contacto con los clientes o usuarios de las organizaciones ${ }^{2}$. Esta respuesta presenta los síntomas de deterioro cognitivo y de baja realización personal en el trabajo, y viene acompañada de actitudes negativas hacia las personas con las que se trabaja, principalmente clientes y usuarios, y hacia el propio rol profesional.

El burnout es una pérdida progresiva de ilusión, un proceso de desencanto hacia el trabajo que se desarrolla en etapas hasta llegar al límite del agotamiento emocional, desembocando en una situación de incapacidad laboral frecuentemente y requiriendo tratamiento terapéutico para su resolución. Las fases del proceso del burnout se suelen categorizar en las siguientes: fase de entusiasmo, fase de estancamiento, fase de frustración y fase de apatía ${ }^{3}$.

En la actualidad, el paradigma que predomina en el estudio y comprensión del burnout es interaccionista, y pretende identificar y profundizar en los antecedentes organizacionales del mismo, en las variables personales o moduladoras y en las consecuencias derivadas de la interrelación entre estos dos primeros aspectos. De este modo, el análisis de un síndrome tan complejo como el burnout requiere tener en cuenta el papel e interrelación de aspectos individuales, sociales y organizacionales.

Sin perjuicio de la trascendencia de las variables personales, el burnout, en cuanto a patología psicosocial, tiende a desarrollarse especialmente en determinado tipo de profesiones, principalmente las asistenciales. Entre ellas, las profesiones sanitarias son especialmente vulnerables al burnout por la concurrencia de distintos factores. Las altas exigencias del medio sanitario, el contacto directo con las personas, el continuo enfrentamiento al dolor, enfermedad y pérdidas, los desajustes organizacionales y las situaciones excepcionales y de emergencia, condicionan un ritmo de trabajo vertiginoso

\footnotetext{
${ }^{1}$ Vid. CIE-11 en: https://icd.who.int/es (fecha de consulta: 12 de abril de 2021). Acoge la OMS la definición clásica del burnout, que postula la naturaleza tridimensional del síndrome. MASLACH, C. y JACKSON, S.E., "The Measurement of Experienced Burnout", Journal of Organizational Behavior, vol. 2 (1981), pp. 99-113.

2 GIL MONTE, P.R., “Cómo evaluar y prevenir el síndrome de quemarse por el trabajo”, Gestión Práctica de Riesgos Laborales, $\mathrm{n}^{\mathrm{o}} 34$ (2007), p. 45.

${ }^{3}$ Cfr. EDELWICH, J. y BRODSKY, A., Burnout: Stages of Disillusionment in the Helping Professions, Nueva York, Human Sciences Press, 1980, pp. 44 y ss. Algún autor incluye en este proceso una última etapa de aislamiento o fase de estar quemado, en la que el estrés se ha cronificado, provocando pérdida de energía y un sentimiento de vacío que se muestra en forma de distanciamiento social y aislamiento, problemáticas sobre las que si no se interviene pueden provocar consecuencias irreversibles para la salud del trabajador. CHERNISS, C., Professional burnout in human service organizations, Nueva York, Praeger, 1980.
} 
y excesivo, viéndose obligados estos profesionales a gestionar diariamente altos niveles de estrés ${ }^{4}$; estrés que se ha visto acrecentado en el último año como consecuencia de la pandemia del covid- $19^{5}$.

Aunque pudiera parecer lógico, teniendo en cuenta el carácter progresivo del burnout, que las situaciones derivadas del síndrome fueran consideradas como enfermedades profesionales en el personal sanitario, lo cierto es que nuestro sistema de lista no las contempla. Debido a esta limitación, el burnout ha sido reconducido en múltiples ocasiones a la categoría de accidente de trabajo, principalmente a través de las denominadas enfermedades del trabajo ex art. 156.2 e) LGSS. Esta reconducción presenta múltiples problemas en su aplicación práctica; y ello, en tanto en cuanto las denominadas enfermedades del trabajo exigen para ser consideradas como accidentes de trabajo probar que tienen su causa exclusiva en el trabajo, lo que es de difícil acreditación en las psicopatologías, que son esencialmente enfermedades concausales en las que acostumbran a concurrir también elementos extralaborales.

El presente artículo tiene como objetivo fundamental analizar la consideración del burnout como accidente de trabajo, mediante su identificación como enfermedad del trabajo ex art. 156.2 e) LGSS, enfocando el examen singularmente en su incidencia en el ámbito sanitario. Se dirige el estudio, en consecuencia, a las enfermedades del trabajo en sentido estricto, obviando aquellas que derivan del art. 156.2 f) LGSS, que pueden ser calificadas como enfermedades del trabajo genéricas ${ }^{6}$.

\section{La configuración jurídica del burnout a través de su integración jurisprudencial}

La recepción del burnout en nuestro ordenamiento se ha realizado de forma progresiva, y en la medida en que los riesgos psicosociales han ido adquiriendo relevancia en nuestro sistema jurídico.

Prescindiendo de la escasa regulación general sobre riesgos psicosociales, nuestro marco normativo carece de ordenación jurídica específica sobre el fenómeno del burnout; ni en

\footnotetext{
${ }^{4}$ Cfr. MACÍA-RODRÍGUEZ, C. y otros, "Síndrome de burnout en especialistas de medicina interna y factores asociados a su desarrollo", Revista Clínica Española, vol. 220, nº 6 (2020), pp. 331-338; BOUZA, E., GIL MONTE, P.R. y PALOMO, E., "Síndrome de quemarse por el trabajo (burnout) en los médicos de España”, Revista Clínica Española, vol. 220, n 6 (2020), pp. 359-363; y GÓMEZ-URQUIZA, J.L. y otros, "Factores de riesgo y niveles de burnout en enfermeras de atención primaria: una revisión sistemática", Atención Primaria, vol. 49, n⿳0 2 (2017), pp. 77-85.

5 Vid. MORENO-JIMÉNEZ J.E. y otros, "The Job Demands and Resources Related to COVID-19 in Predicting Emotional Exhaustion and Secondary Traumatic Stress Among Health Professionals in Spain", Frontiers in Psychology, no 12 (2021); y BUENO FERRÁN, M. y BARRIENTOS-TRIGO, S., "Cuidar al que cuida: el impacto emocional de la epidemia de coronavirus en las enfermeras y otros profesionales de la salud", Enfermería Clínica, vol. 31, nº extra. 1 (2021), pp. 35-39.

${ }^{6}$ Se acoge la categorización de SÁNCHEZ PÉREZ, J., La configuración jurídica del accidente de trabajo, Murcia, Ediciones Laborum, 2011, pp. 290-291. Otro sector doctrinal ha considerado a las contingencias incluidas en el art. 156.2 f) LGSS como asimilaciones específicas al accidente de trabajo, en contraste con la asimilación general del art. 156.2 e) LGSS. Cfr. GONZÁLEZ ORTEGA, S., "Las enfermedades profesionales: Un concepto de delimitación compleja para un fenómeno social de relevancia", en AAVV, Las enfermedades profesionales, Valencia, Tirant lo Blanch, 2017, p. 35.
} 
la normativa laboral stricto $\operatorname{sensu}^{7}$, ni en las normas de seguridad $\operatorname{social}^{8}$, ni en las disposiciones preventivas ${ }^{9}$, se encuentran referencias explícitas al burnout.

La ausencia de disposiciones específicas no implica que el ordenamiento jurídico carezca de instrumentos que permitan tutelar el fenómeno del burnout; tutela que puede ser proporcionada por la extensa normativa laboral y preventiva con la que cuenta nuestro ordenamiento, a través de un simple proceso de aplicación de los criterios hermenéuticos generales contenidos en el art. $3.1 \mathrm{CC}^{10}$.

En este contexto, han sido jueces y tribunales los que han introducido al burnout en nuestra realidad jurídica, principalmente a través de sus resoluciones en materia laboral, y específicamente en el ámbito de la seguridad social y en el preventivo ${ }^{11}$. Así, la jurisdicción social ha ido conformando un concepto jurídico del síndrome de estar quemado que, esencialmente, ha partido del concepto clínico consensuado en los estudios científicos realizados sobre la materia en el campo de la psicología de las organizaciones y de la medicina del trabajo ${ }^{12}$.

Se suele señalar como resolución pionera del reconocimiento del burnout en España la dictada por el TSJ País Vasco de 2 de noviembre de 1999, que califica el síndrome de estar quemado sufrido por un trabajador como contingencia profesional ${ }^{13}$. Tras esta primera resolución, múltiples pronunciamientos judiciales se han ido dictando en relación con el burnout, coadyuvando todos ellos a conformar una concepción jurídica del síndrome que se concreta en los siguientes elementos:

- Concepto. Enfermedad psicosocial de "nueva aparición (...) y que se trata de un síndrome de agotamiento físico y mental intenso, resultado de un estado de estrés

\footnotetext{
${ }^{7}$ Cfr. GALA DURÁN, C., "El síndrome de «estar quemado» o de agotamiento profesional y su calificación como accidente de trabajo", La administración práctica, no 12 (2018), pp. 85-96.

${ }^{8}$ ROJAS RIVERO, G.P., "Los llamados riesgos emergentes de carácter psicosocial vinculados al trabajo", en AAVV, Accidentes de trabajo y enfermedades profesionales. Experiencias y desafíos de una protección social centenaria (II), Murcia, Ediciones Laborum, 2020, p. 198.

9 RODRÍGUEZ ESCANCIANO, S., "Los riesgos psicosociales en el teletrabajo a domicilio bajo las coordenadas de la nueva economía «low touch»", en AAVV, Accidentes de trabajo y enfermedades profesionales. Experiencias y desafios de una protección social centenaria (II), op. cit., p. 679.

${ }^{10}$ GONZÁLEZ DE PATTO, R.M ${ }^{\mathrm{a}}$., "El síndrome de desgaste personal o de burn out y las técnicas jurídicolaborales de tutela: reflexiones en torno a la sentencia del Juzgado de lo Social núm. 16 de Barcelona de 27 de diciembre de 2002", Actualidad Laboral, no 35 (2003), pp. 617 y ss.

${ }^{11}$ Sin perjuicio de la indudable trascendencia del iuslaboralismo en el reconocimiento jurídico del burnout, el síndrome también ha sido objeto de examen, aunque de forma puntual, en ámbitos extralaborales, como en el derecho civil y en el derecho de seguros. Cfr. SAP Islas Baleares de 26 marzo de 2013 (JUR 2013, 164914), SAP Albacete de 17 de diciembre de 2019 (JUR 2020, 84767) y SAP Sevilla de 23 septiembre de 2011 (JUR 2012, 1077).

${ }^{12}$ GONZÁLEZ DE PATTO, R.M"a ., "El síndrome de desgaste personal o de burn out y las técnicas jurídicolaborales de tutela: reflexiones en torno a la sentencia del Juzgado de lo Social núm. 16 de Barcelona de 27 de diciembre de 2002", op. cit., pp. 617 y ss. La traslación directa del concepto clínico del burnout al ámbito jurídico ha sido considerada poco acertada para un sector doctrinal, que aboga por adoptar un concepto jurídico del síndrome de estar quemado menos vinculado con su dimensión clínica. Vid. VALLEJO DACOSTA, R., Riesgos psico-sociales: prevención, reparación y tutela sancionadora, Cizur Menor, Aranzadi, 2005, p. 142.

${ }^{13}$ STSJ País Vasco de 2 de noviembre de 1999 (AS 1999, 4212). La resolución fue recurrida en casación para la unificación de doctrina, recurso que fue inadmitido por ATS de 26 de octubre de 2000 ( $\mathrm{n}^{\circ}$ rec. 4379/1999).
} 
laboral crónico o frustración prolongado y que según tanto la Psicología del Trabajo como la Medicina Forense se trata de un trastorno de adaptación del individuo al ámbito laboral cuya caracterización reside en el cansancio emocional (pérdida progresiva de energía, desgaste, agotamiento y fatiga emocional)"14. Se considera como una enfermedad "propia del estilo de vida de este siglo y es un estado de agotamiento físico, emocional y mental, causado por el involucrarse en situaciones emocionalmente demandantes, durante un tiempo prolongado" ${ }^{15}$.

- El burnout como proceso. El síndrome de estar quemado no surge de manera súbita, "sino que es un proceso continuo, es un estrés de carácter crónico experimentado en el contexto laboral" ${ }^{16}$. Se desarrolla gradualmente y pasa por cuatro fases: "a) una primera fase idealista, caracterizada por el alto nivel de energía y expectativas depositadas en el trabajo; b) una segunda fase de sobreesfuerzo en la que el individuo advierte que sus esfuerzos no están a la altura de sus expectativas, ni le son reconocidos; c) una tercera fase de desilusión y paralela frustración, en la que aparece la desilusión, acompañada de fatiga, mientras incrementa el esfuerzo invertido esperando todavía una recompensa apropiada, cuya ausencia determina impaciencia e irritabilidad; y d) la fase final de desmoralización, caracterizada por la pérdida de interés en el trabajo e incapacidad de trabajar y de relacionarse socialmente en el entorno laboral" ${ }^{17}$.

- Causas. Respecto a sus causas, "se apunta como estresores laborales desencadenantes, los vinculados al puesto de trabajo y las variables de carácter personal" 18 .

- Consecuencias. El trabajador "presenta síntomas de agotamiento emocional, cansancio físico y psicológico. En su intento de aliviar esta situación trata de aislarse, desarrollando una actitud fría y despersonalizada en relación con los demás, mostrando una falta de compromiso con el trabajo. Se da un sentimiento de inadecuación, incompetencia, ineficacia, etc., de no poder atender debidamente las tareas"19. Así, "el «quemado» por el trabajo, se ha dicho, tiene fuerzas, pero no tiene ganas; la despersonalización, manifestada en falta de realización personal, sentimientos de frustración, inutilidad, desinterés progresivo hacia el trabajo con rutinización de tareas; aislamiento del entorno laboral y social y, frecuentemente, ansiedad, depresión (trastorno psíquico adaptativo crónico)"20. La lista de síntomas psicológicos que puede originar este síndrome es extensa, pudiendo ser leves, moderados, graves o extremos, y categorizarse de la siguiente manera: "1. Físicos: fatiga, problemas del sueño, dolores de cabeza, impotencia,

\footnotetext{
${ }^{14}$ STSJ Navarra de 5 de marzo de 2014 (JUR 2014, 118970).

15 STSJ Andalucía (Granada) de 13 de febrero de 2020 (JUR 2020, 187961).

${ }^{16}$ STSJ País Vasco de 2 de noviembre de 1999 (AS 1999, 4212).

${ }^{17}$ STSJ Cataluña de 20 de enero de 2005 (AS 2005, 31).

18 STSJ Navarra de 5 de marzo de 2014 (JUR 2014, 118970) y STSJ Andalucía (Granada) de 10 enero de 2007 (AS 2008, 53)

${ }^{19}$ STSJ País Vasco de 2 de noviembre de 1999 (AS 1999, 4212).

${ }^{20}$ STSJ Navarra de 5 de marzo de 2014 (JUR 2014, 118970).
} 
gastrointestinales, etc. 2. Emocionales: irritabilidad, ansiedad, depresión, desesperanza, etc. 3. Conductuales: agresión, actitud defensiva, cinismo, abuso de sustancias, etc. 4. Relacionados con el trabajo: ausentismo, falta de rendimiento, robos, etc. 5. Interpersonales: pobre comunicación, falta de concentración, aislamiento" 21 .

Junto con la delimitación positiva, los órganos jurisdiccionales también han realizado una labor de concreción en sentido negativo del burnout, diferenciando el síndrome de "los conflictos laborales, el estrés laboral y las exigencias profesionales legítimas dentro de la organización laboral" 22 . Con todo, la principal delimitación negativa del burnout ha operado en lo que atañe a su distinción de los fenómenos de acoso laboral o mobbing. Pese a que el burnout y el mobbing constituyen materializaciones de los riesgos psicosociales y presentan consecuencias similares para los trabajadores afectados, el origen, las causas y los mecanismos que desencadenan una u otra realidad son completamente diferentes. Así, "aun cuando ambas patologías psicosociales coinciden en el resultado, esto es, los graves daños que producen en la salud del trabajador, el acoso moral o mobbing se integra por un elemento intencional lesivo, ya proceda del empleador o superiores jerárquicos (bossing) o por compañeros (mobbing horizontal), sin embargo en el burnout, ese elemento intencional está, en principio, ausente" 23 .

Como se puede comprobar por el sucinto análisis realizado, la jurisprudencia no ha hecho sino plasmar jurídicamente las evidencias científicas que sobre el burnout se derivan de la psicología de las organizaciones y de la medicina del trabajo, acogiendo, sin apenas matices, las tesis más ortodoxas en lo relacionado con la conceptualización del síndrome ${ }^{24}$.

\section{El personal sanitario como colectivo especialmente expuesto al burnout}

El burnout no resulta un fenómeno que concurra de forma exclusiva en una actividad concreta, sino que puede afectar a trabajadores de todo tipo y en variados entornos laborales $^{25}$. No obstante, existen ciertas profesiones que parecen tener más tendencia a padecer el síndrome de estar quemado que otras, resultando especialmente relevantes a estos efectos aquellas de carácter asistencial o que trabajan con personas. En los distintos estudios realizados sobre este extremo, se evidencia que, en general, las profesiones que

\footnotetext{
${ }^{21}$ STSJ Andalucía (Granada) de 13 de febrero de 2020 (JUR 2020, 187961).

22 STSJ Madrid de 15 febrero de 2019 (JUR 2019, 330782).

${ }^{23}$ STSJ Navarra de 5 de marzo de 2014 (JUR 2014, 118970). Vid. STS de 16 de febrero de 2011 (RJ 2011, 3365). Cfr. STSJ Madrid de 14 mayo de 2020 (JUR 2020, 246492) y STSJ Aragón de 5 febrero de 2020 (JUR 2020, 104112).

${ }^{24}$ BARREIRO GONZÁLEZ, G. (dir.), Las enfermedades del trabajo: nuevos riesgos psicosociales y su valoración en el derecho de la protección social, Madrid, Ministerio de Trabajo y Asuntos Sociales, 2007, p. 78. Disponible en https://www.diba.cat/documents/467843/69764218/100517.pdf/7e8912f5-f474-40a7a7c9-86fc96abeb10 (fecha de consulta: 11 de marzo de 2021).

${ }^{25}$ CAÑADAS-DE LA FUENTE, G.A. y otros, "Evidencia de validez factorial del Maslach Burnout Inventory y estudio de los niveles de burnout en profesionales sanitarios", Revista Latinoamericana de Psicología, vol. 46, $\mathrm{n}^{\circ} 1$ (2014), pp. 44-52; y LOZANO, M.L. y otros, "Descripción de los niveles de Burnout en diferentes colectivos profesionales", Aula Abierta, vol. 36, no 1-2 (2008), pp. 79-88.
} 
se asocian en mayor medida al burnout son aquellas en las que se producen interacciones entre trabajador y cliente de forma intensa, al ser profesiones de servicio o asistenciales. Suelen ser, además, ocupaciones cuyos trabajadores presentan un alto grado de autoexigencia y elevadas expectativas que comportan un gran desgaste emocional. En este sentido, la confluencia de la vulnerabilidad inherente a las profesiones que prestan atención directa e intensa a personas y exigen un alto nivel de compromiso profesional y personal, junto con las situaciones laborales negativas y estresantes, constituyen un contexto típicamente favorecedor del desarrollo del burnout $t^{26}$.

Dos son los colectivos laborales en los que se concentran el mayor número de trabajos y en los que se han hallado importantes niveles de burnout: las profesiones sanitarias y las relacionadas con la docencia ${ }^{27}$. La mayor vulnerabilidad de estos colectivos ha tenido su reflejo en la jurisprudencia, que ha considerado que el burnout constituye "un tipo muy característico de estrés que se da en aquellas profesiones de quienes realizan su trabajo en contacto con otras personas que, por sus características, son sujetos de ayuda (profesores, personal sanitario, asistentes sociales, etc.), y surge al ver el profesional defraudadas sus expectativas al verse imposibilitado de modificar la situación laboral y de poder poner en práctica sus ideas con respecto a cómo debe ser realizado su trabajo"28. En este sentido, puede calificarse como un "estrés laboral asistencial, y por consiguiente con más incidencia en el sector servicios, de entre los que cabe destacar los servicios sociales en los que el trabajo se realiza en contacto directo con personas que por sus características son sujetos de ayuda" 29 . Es especialmente relevante en aquellos que "trabajan en profesiones que se encuentran en íntima relación con el sufrimiento humano (tales como psicoterapeutas, médicos, enfermeros, personal de rescate, etc." ${ }^{30}$.

Centrando el análisis en el personal sanitario, se pueden encontrar una gran cantidad de investigaciones sobre el burnout en este colectivo de trabajadores. Las altas exigencias del medio sanitario, el constante contacto directo con las personas, el continuo enfrentamiento al dolor, enfermedad y pérdidas, los desajustes organizacionales y las situaciones excepcionales y de emergencia, entre otros factores, condicionan un ritmo de trabajo vertiginoso y excesivo, viéndose obligados estos profesionales a gestionar diariamente altos niveles de estrés ${ }^{31}$; estrés que se ha visto acrecentado en el último año

\footnotetext{
${ }^{26}$ La especial incidencia del burnout en las profesiones asistenciales se ha visto reflejada en la jurisprudencia, que ha reconocido determinados pluses de peligrosidad relacionados con la exposición al síndrome en este tipo de ocupaciones. Por todas, STSJ Galicia de 7 noviembre de 2003 (JUR 2004, 168128). En todo caso, la procedencia de este tipo de pluses no deriva del sector de actividad en el que se incardine la profesión desempeñada, sino que se anuda a la concreta tarea que se realice. Vid. SJS no 1 Vigo de 13 marzo de 1999 (AS 1999, 800).

27 LLANEZA ÁlVAREZ, F.J., La ergonomía forense. Pruebas periciales en prevención de riesgos laborales, Valladolid, Lex Nova, $2^{\text {a }}$ ed., 2007, pp. 210-212.

${ }^{28}$ STSJ País Vasco de 2 de noviembre de 1999 (AS 1999, 4212).

${ }^{29}$ STSJ Navarra de 5 de marzo de 2014 (JUR 2014, 118970).

${ }^{30}$ STSJ Andalucía (Granada) de 13 de febrero de 2020 (JUR 2020, 187961).

${ }^{31}$ Cfr. MACÍA-RODRÍGUEZ, C. y otros, "Síndrome de burnout en especialistas de medicina interna y factores asociados a su desarrollo", op. cit., pp. 331-338; BOUZA, E., GIL MONTE, P.R. y PALOMO, E., "Síndrome de quemarse por el trabajo (burnout) en los médicos de España", op. cit., pp. 359-363; y GÓMEZ-URQUIZA, J.L. y otros, "Factores de riesgo y niveles de burnout en enfermeras de atención primaria: una revisión sistemática”, op. cit., pp. 77-85.
} 
por la sobrecarga laboral consecuencia de la pandemia del covid-19. El exceso de trabajo que el personal sanitario ha soportado durante la crisis sanitaria del covid-19, tanto cuantitativo, por exceso de tareas, como cualitativo, por la dificultad de las tareas a realizar y la escasez de medios disponibles, ha generado un contexto laboral altamente proclive al desarrollo del síndrome del trabajador quemado ${ }^{32}$.

La vulnerabilidad del personal sanitario para desarrollar burnout parece estar asociada a múltiples factores, si bien los derechos indiscriminados de los pacientes se presentan como una de las fuentes principales de estrés laboral. El cambio de paradigma cultural actual, asociado a un modelo que ha sido denominado gráficamente como "sociedad de la queja", ha provocado la degradación progresiva de los sanitarios, que en la actualidad apenas son objeto de reconocimiento social. El sanitario, que durante muchos años fue uno de los agentes sociales más importantes y con mayor estatus sociocultural y económico, se ha convertido en un miembro más del funcionariado, con escaso reconocimiento social y elevadas exigencias por parte de los pacientes ${ }^{33}$. De este modo, la frecuencia e intensidad con la que concurren los conflictos interpersonales en las profesiones asistenciales parecen tener una fuerte asociación con la aparición y desarrollo de estrés y del síndrome de burnout en el personal sanitario ${ }^{34}$.

Reflejo paradigmático de lo anteriormente expuesto es que cada vez hay un mayor número de denuncias por agresiones físicas y/o verbales en el ámbito sanitario y, en general, en todas las de carácter asistencial. El sector sanitario se ha visto afectado por un incremento exponencial de agresiones y faltas de respeto a sus profesionales. Los últimos estudios que se han realizado sobre este particular evidencian un incremento en la magnitud de la violencia contra el personal sanitario en los últimos años, que acostumbra a responder a un mismo patrón ${ }^{35}$ :

- En la mayoría de los casos los agresores son hombres, siendo generalmente las profesionales agredidas mujeres.

- El tipo de agresión es fundamentalmente verbal y psicológica, acompañada de amenazas. Con todo, también concurren en múltiples ocasiones agresiones físicas.

- Los principales agresores son los pacientes y los sujetos agredidos generalmente médicos y profesionales de enfermería.

\footnotetext{
32 GARCÍA-IGLESIAS, J.J. y otros, "Impacto del SARS-COV-2 (covid-19) en la salud mental de los profesionales sanitarios: una revisión sistemática”, Revista Española de Salud Pública, vol. 94 (2020).

${ }^{33}$ GIL MONTE, P.R., El síndrome de quemarse por el trabajo (burnout). Una enfermedad laboral en la sociedad del bienestar, Madrid, Pirámide, $4^{\circ}$ ed., 2015, p. 72.

${ }^{34}$ BALDWIN Jr, D.C. y DAUGHERTY, S.R., "Interprofessional conflict and medical errors: results of a national multi-specialty survey of hospital residents in the US", Journal of Interprofessional Care, vol. 22, no 6 (2008), pp. 573-586; JERNG, J. S. y otros, "Workplace interpersonal conflicts among the healthcare workers: Retrospective exploration from the institutional incident reporting system of a university-affiliated medical center", PloS One, vol. 12, n 2 (2017); y LANZ, J.J. y BRUK-LEE, V., "Resilience as a moderator of the indirect effects of conflict and workload on job outcomes among nurses", Journal of Advanced Nursing, vol. 73, nº 12 (2017), pp. 2973- 2986.

35 Vid. SERRANO VICENTE, M.I. y otros, “Agresiones a profesionales del sector sanitario en España, revisión sistemática”, Revista Española de Salud Pública, vol. 93 (2019).
} 
- Las causas que generan este tipo de agresiones de forma inmediata son los tiempos de espera y la demora en la prestación del servicio.

- Un alto porcentaje de trabajadores sanitarios perciben las agresiones como un factor más de su trabajo al que están expuestos ${ }^{36}$.

La falta de reconocimiento social, la pérdida paulatina de prestigio y los comportamientos agresivos hacia el personal sanitario, provocan en estos profesionales problemas de salud a nivel físico y emocional y comportan la pérdida del sentido y valor del trabajo, lo que finalmente aboca al desarrollo del burnout; síndrome que se presenta como especialmente significativo en este colectivo profesional.

\section{El burnout y su calificación como contingencia profesional: consideraciones previas}

Resulta evidente que, desde una óptica prestacional, nuestro actual sistema de seguridad social otorga distinto tratamiento a las contingencias protegidas según sean consideradas como profesionales o comunes. Así, los periodos de carencia, la automaticidad de las prestaciones, su cuantía o las bases de cotización aplicables, son diferentes para los casos de accidentes de trabajo o enfermedades profesionales y para las denominadas contingencias comunes. Además de los elementos apuntados, de indudable relevancia, la calificación de un supuesto como contingencia profesional supone que despliegue toda su eficacia la normativa preventiva, normativa que tiene su campo de acción natural en el ámbito de las contingencias profesionales ${ }^{37}$. Este diferente tratamiento, que conlleva una mayor protección de las situaciones calificadas como contingencia profesional, justifica la especial "litigiosidad para aprehender una situación causante de las prestaciones como inserta dentro de la contingencia profesional y no en la común"38.

Aunque, prima facie, podría parecer lógico teniendo en cuenta el carácter progresivo del burnout que las situaciones derivadas del síndrome fueran consideradas como enfermedades profesionales, lo cierto es que, como posteriormente se examinará, las mismas han sido reconducidas como accidentes de trabajo, principalmente a través de las denominadas enfermedades del trabajo ex art. 156.2 e) LGSS; y ello, por las propias limitaciones que la configuración del sistema de enfermedades profesionales español presenta.

\footnotetext{
${ }^{36}$ Cfr. ORTELLS ABUYÉ, N. y otros, "Caracterización de las agresiones producidas al personal sanitario del servicio de urgencias en un hospital comarcal", Enfermería Global, vol. 12, nº 30 (2013), pp. 196-207. 37 Sobre los problemas jurídicos más importantes que plantea la naturaleza y determinación de las contingencias protegidas por el sistema de seguridad social, vid. MONEREO PÉREZ, J.L. y FERNÁNDEZ AVILÉS, J.A., "Determinación de contingencias de la Seguridad Social", Aranzadi Social, no 19 (2019), pp. 69-112.

${ }^{38}$ URRUTIKOETXEA BARRUTIA, M., "Suicidio y accidente de trabajo", Revista de Derecho Social, $\mathrm{n}^{\circ}$ 41 (2008), pp. 169-192. Esta litigiosidad se plantea en toda su extensión en relación con el síndrome de estar quemado, estando en la génesis de gran parte de las reclamaciones que se efectúan sobre la materia la determinación de la naturaleza común o profesional del burnout. TEJERO ACEVEDO, R., GONZÁLEZ TRIJUEQUE, D. y DELGADO MARINA, S., "El burnout como forma de estrés laboral y su dimensión forense", Revista Cubana de Salud y Trabajo, vol. 14, nº 1 (2013), p. 56.
} 
En España, el modelo de enfermedades profesionales en vigor es formalmente un sistema de lista, tal y como se desprende del art. 157 LGSS: se "entenderá por enfermedad profesional la contraída a consecuencia del trabajo ejecutado por cuenta ajena en las actividades que se especifiquen en el cuadro que se apruebe por las disposiciones de aplicación y desarrollo de esta Ley, y que esté provocada por la acción de los elementos o sustancias que en dicho cuadro se indiquen para cada enfermedad profesional". Actualmente, ese cuadro de enfermedades profesionales se encuentra en el RD 1299/2006, de 10 de noviembre, por el que se aprueba el cuadro de enfermedades profesionales en el sistema de la Seguridad Social y se establecen criterios para su notificación y registro.

El sistema de lista presenta indudables beneficios derivados de la seguridad jurídica implícita en el mismo. Entre otras ventajas, simplifica el diagnóstico, reduce los litigios y facilita el acceso a las prestaciones ${ }^{39}$.

Como contrapunto, esta seguridad jurídica incide en una mayor rigidez del sistema, que no permite a priori calificar como enfermedades profesionales otras patologías de clara etiología laboral, salvo que exista una reforma normativa que así las considere mediante su inclusión en el listado reglado.

Sin perjuicio de lo anterior, el sistema de lista se convierte en la práctica en nuestro ordenamiento jurídico en un modelo mixto. En este sentido, las imprecisiones, ambigüedades y expresiones de carácter enunciativo que contiene el RD 1299/2006, han transformado el sistema formal de lista en un sistema abierto, principalmente a través de la acción interpretativa de los órganos jurisdiccionales ${ }^{40}$.

Centrando el análisis en el burnout, su no inclusión en el cuadro de enfermedades profesionales ha merecido una valoración muy crítica para la doctrina mayoritaria. Así, se ha señalado que una patología como la del síndrome del trabajador quemado, de cuya propia denominación puede ya deducirse su conexión directa con la relación profesional de trabajo, y que constituye una dolencia propia de la existencia de riesgos psicosociales, debería calificarse automáticamente como enfermedad profesional ${ }^{41}$.

39 LÓPEZ GANDÍA, J. y AGUDO DÍAZ, J., Nueva regulación de las enfermedades profesionales, Albacete, Bomarzo, 2007, p. 16.

40 LEGUA RODRIGO, Ma .C., "Concepto legal y concepto doctrinal de enfermedad profesional: interpretación jurisprudencial de la lista de enfermedades profesionales del RD 1299/2006", Revista de Derecho de la Seguridad Social, no 20 (2019), pp. 71 y ss.; y POQUET CATALÁ, R., "El sistema de calificación de enfermedades profesionales y la posible inclusión de nuevas profesiones", Trabajo y Derecho, no 39 (2018), pp. 71-81. Cfr. SSTS de 23 de octubre de 2008 (RJ 2008, 7395), de 8 de octubre de 2009 (RJ 2010, 1133), de 5 de noviembre de 2014 (RJ 2014, 6326), de 11 de febrero 2020 (RJ 2020, 805) y de 10 de marzo de 2020 (RJ 2020, 1416). Con todo, existen pronunciamientos judiciales que mantienen una interpretación estricta del listado y no admiten ningún tipo de enfermedad más allá de la literalidad de la norma. Cfr. STSJ Cataluña de 29 de marzo de 2019 (JUR 2019, 174125) y STSJ Cantabria de 10 de diciembre de 2019 (JUR 2020, 11524).

${ }^{41}$ SÁNCHEZ PÉREZ, J., "El síndrome del trabajador quemado (burn out): su contenido y su polémico encuadramiento jurídico-laboral", Revista de Información Laboral, no 5 (2016), pp. 31-50; IGARTUA MIRÓ, Ma . T., "La nueva lista de enfermedades profesionales y la inamovilidad respecto de las dolencias derivadas de riesgos psicosociales", Actualidad Laboral, no 22 (2007), pp. 2692 y ss.; CONTRERAS HERNÁNDEZ, O., "La inclusión de los riesgos psicosociales en el cuadro de enfermedades profesionales: evidencias y propuestas para una revisión legal", en AAVV, Accidentes de trabajo y enfermedades 
Parece incuestionable que la propia naturaleza, identidad y definición del burnout hacen aconsejable su inclusión en el cuadro de enfermedades profesionales; inclusión que también viene avalada por los organismos internacionales. A este respecto, resulta esencial la Recomendación $\mathrm{n}^{\circ} 194$ OIT sobre la lista de enfermedades profesionales (2002), que en su revisión de 2010 incorpora a ese listado los trastornos mentales o del comportamiento "cuando se haya establecido, científicamente o por métodos adecuados a las condiciones y la práctica nacionales, un vínculo directo entre la exposición a factores de riesgo que resulte de las actividades laborales y el(los) trastorno(s) mental(es) o del comportamiento contraído(s) por el trabajador" ${ }^{\prime 2}$.

La no incorporación de una enfermedad de etiología tan netamente laboral como el burnout en el listado de enfermedades profesionales, no hace sino evidenciar que dicho catálogo requiere de una reformulación que le permita acomodarse a las nuevas patologías que de modo incesante van surgiendo como consecuencia de las nuevas formas de organización productiva, esencialmente marcadas por las tecnologías de la información y la comunicación ${ }^{43}$. El relativo quietismo del legislador en este punto ha conformado un catálogo de enfermedades que ha sido entendido como in fieri, constituyendo su renovación uno de los retos más importantes de nuestro país en lo que atañe al sistema protector de la seguridad social ${ }^{44}$.

La calificación del burnout como enfermedad profesional dotaría al sistema de seguridad social de mayor certeza jurídica, evitando las artificiosas y forzadas derivaciones que de este síndrome se realizan hacia el concepto de accidente de trabajo. Sin desmerecer la labor doctrinal y jurisprudencial que ha articulado la protección del burnout a través de las referidas desviaciones, amparadas principalmente en el concepto de enfermedad del trabajo del art. 156.2 e) LGSS, parece mucho más lógico y ortodoxo otorgar protección al síndrome de estar quemado mediante su inclusión en el listado de enfermedades profesionales ${ }^{45}$.

El sistema de lista de enfermedades profesionales vigente en España, relativamente rígido en este punto, hace difícil la inclusión de burnout en el mismo sin que exista una reforma normativa previa ${ }^{46}$. La reciente incorporación por la OMS del burnout como una

profesionales. Experiencias y desafíos de una protección social centenaria(I), Murcia, Ediciones Laborum, 2020, pp. 442-443; y, desde el ámbito de la psicología del trabajo, GIL MONTE, P.R., El síndrome de quemarse por el trabajo (burnout). Una enfermedad laboral en la sociedad del bienestar, op. cit., pp. 3132.

42 TEJERO ACEVEDO, R., GONZÁLEZ TRIJUEQUE, D. y DELGADO MARINA, S., "El burnout como forma de estrés laboral y su dimensión forense", op. cit., p. 58.

${ }^{43}$ CAVAS MARTÍNEZ, F., "Aspectos jurídicos de la enfermedad profesional: estado de la cuestión y propuestas de reforma", Medicina y Seguridad del Trabajo, suplemento extraordinario (2016), pp. 78-86.

${ }^{4}$ SÁNCHEZ PÉREZ, J., "El síndrome del trabajador quemado (burn out): su contenido y su polémico encuadramiento jurídico-laboral", op. cit., pp. 31-50. Cfr. las propuestas de CONTRERAS HERNÁNDEZ, O., "La inclusión de los riesgos psicosociales en el cuadro de enfermedades profesionales: evidencias y propuestas para una revisión legal”, op. cit., pp. 443-444.

${ }^{45}$ Cfr. STSJ Castilla y León (Valladolid) de 6 junio de 2013 (JUR 2013, 217982).

${ }^{46}$ Actualización que ha sido reclamada por doctrina y jurisprudencia desde hace años en lo relativo con los riesgos psicosociales. Por todos, cfr. IGARTUA MIRÓ, M'.T., "La nueva lista de enfermedades profesionales y la inamovilidad respecto de las dolencias derivadas de los riesgos psicosociales", op. cit., pp. 2692-2705, y STSJ Murcia de 24 de mayo de 2004 (AS 2004, 1571). 
problemática o fenómeno asociado al trabajo, tras la revisión decimoprimera de la CIEaprobada en 2019 y que ha fijado como fecha de entrada en vigor el 1 de enero de 2022podría constituir un buen punto de partida para una posible modificación del cuadro de enfermedades profesionales que permitiera la inclusión del burnout entre las patologías que merecen tal consideración.

El hecho de que el ordenamiento jurídico interno no contemple expresamente los daños psíquicos, entre los que se incardinan los derivados del burnout, en el listado de enfermedades profesionales, dificulta la calificación del síndrome como contingencia profesional. Con el fin de dispensar al burnout la protección propia de las contingencias profesionales, han sido varios los instrumentos jurídicos y hermenéuticos empleados para reconducirlo a la contingencia de accidente de trabajo, principalmente con base en el concepto de enfermedad del trabajo ex art. 156.2 e) LGSS. A analizar este extremo se dedican los siguientes apartados del presente estudio.

\section{Los trastornos psicosociales como enfermedades del trabajo: elementos delimitadores}

Teniendo en cuenta la inherente vinculación del burnout con el medio laboral, que acentúa su naturaleza profesional, doctrina y jurisprudencia han considerado que este síndrome se debe reconducir a accidente de trabajo ex art. 156.2 e) LGSS. De conformidad con el referido precepto, tendrán la consideración de accidentes de trabajo las enfermedades que, sin ser profesionales, "contraiga el trabajador con motivo de la realización de su trabajo, siempre que se pruebe que la enfermedad tuvo por causa exclusiva la ejecución del mismo".

A este tipo de enfermedades, que, sin ser en sentido técnico-jurídico profesionales al no encontrarse incluidas en el RD 1299/2006, tienen una relación causal con el trabajo, y, por ello, se equiparan a los accidentes de trabajo, se les denomina habitualmente enfermedades del trabajo, "concepto «sui generis» diverso de los de accidente de trabajo y enfermedad profesional, que constituye una figura intermedia dentro de la categoría jurídica de los riesgos profesionales cuya funcionalidad cobra hoy especial sentido ante el desbordamiento de la fenomenología de los riesgos laborales que refleja la existencia de lo que se ha venido en llamar una «sociedad del riesgo»"47.

Retomando el art. 156.2 e) LGSS, del propio literal de la norma se desprende que solo cuando la enfermedad derive del trabajo como causa exclusiva podrá tener la misma la consideración de accidente de trabajo. El carácter exclusivo de la causa genera múltiples problemas en su aplicación práctica, resultando singularmente relevante en lo que atañe a las psicopatologías, al ser esencialmente enfermedades concausales en las que

\footnotetext{
47 STSJ Navarra de 5 de marzo de 2014 (JUR 2014, 118970). Algún sector doctrinal ha asimilado las enfermedades encuadrables en el art. 156.2 e) LGSS a enfermedades profesionales no listadas. Vid. MARTÍNEZ BARROSO, Ma.R., "Sobre las enfermedades profesionales no listadas (A propósito de un supuesto de síndrome de desgaste personal o de burn-out)", Revista de Derecho Social, no 10 (2000), p. 189.
} 
acostumbran a concurrir también elementos extralaborales ${ }^{48}$. Esta problemática se ve acrecentada por el hecho de que la presunción del art. 156.3 LGSS no resulte aplicable con carácter general a las enfermedades del trabajo, tal y como se desprende de una interpretación literal del referido precepto. Con todo, la jurisprudencia ha venido extendiendo su aplicación en aquellos supuestos en que la patología se presente de forma súbita y violenta en tiempo y lugar de trabajo, lo que excluye los supuestos acumulativos y graduales, como es el caso de burnout ${ }^{49}$.

Con el fin de que el art. 156.2 e) LGSS no perdiera su eficacia y virtualidad práctica, la jurisprudencia ha tenido que realizar una relectura del precepto, flexibilizando y reinterpretando el carácter de exclusividad laboral de la causa que se exige para considerar una enfermedad -especialmente las de etiología psicosocial- como accidente de trabajo. Los criterios de elaboración jurisprudencial en relación con este asunto se pueden sintetizar en los siguientes elementos ${ }^{50}$ :

- Las alteraciones psicológicas muestran una etiología heterogénea, ofreciendo una diversidad de posibles causas entre las que se encuentran también las de naturaleza laboral. La determinación de las relaciones de causalidad entre trabajo y lesión es por lo general casuística, y por ello resulta difícil establecer criterios generales sobre supuestos en los que se considera que concurre dicha conexión o aquellos otros en los que se rechaza ${ }^{51}$.

- Cualquier psicopatología que guarde relación con el entorno laboral no puede ser calificada como accidente de trabajo ${ }^{52}$. Así, el hecho de que una enfermedad de etiología común se revele exteriormente con ocasión del ejercicio del trabajo no dota a la misma, sin más, de la característica jurídica de accidente de trabajo, en tanto en cuanto no se demuestre la efectiva influencia del trabajo en la aparición de la enfermedad ${ }^{53}$. En idénticos términos, la existencia de una psicopatología en concurrencia con riesgos psicosociales no constituye por sí misma causa suficiente para entender una determinada enfermedad como accidente de trabajo, sino que se debe acreditar que la patología se ha contraído de forma exclusiva con motivo de la realización del trabajo por cuenta ajena ${ }^{54}$.

- Para que una enfermedad pueda ser considerada como accidente de trabajo de acuerdo con el art. 156.2 e) LGSS, no basta con que el trabajo sea un elemento

\footnotetext{
${ }^{48}$ Cfr. GONZÁLEZ ORTEGA, S., "Las enfermedades profesionales: un concepto de delimitación compleja para un fenómeno social de relevancia", op. cit., p. 36

${ }^{49}$ MARTÍNEZ BARROSO, Ma .R., "La consideración de la actitud pasiva empresarial ante el hostigamiento psicológico como incumplimiento preventivo y recargo de prestaciones en supuestos de laboralidad de mobbing", Relaciones Laborales, $\mathrm{n}^{\circ} 11$ (2010), pp. 629-658.

${ }^{50}$ Vid. STSJ Andalucía (Sevilla) de 29 junio de 2017 (JUR 2017, 213024), STSJ Aragón de 25 septiembre de 2013 (JUR 2014, 16148) y STSJ Navarra de 5 de marzo de 2014 (JUR 2014, 118970).

${ }^{51}$ STSJ Andalucía (Granada) de 13 febrero de 2020 (JUR 2020, 187961).

52 STSJ Canarias (Las Palmas) de 22 de julio de 2008 (JUR 2009, 55020). Vid. STSJ Navarra de 8 septiembre de 2009 (AS 2009, 2808), STSJ Aragón de 25 septiembre de 2013 (JUR 2014, 16148) y STSJ Extremadura de 27 enero de 2005 (AS 2005, 82).

${ }^{53}$ STS de 24 de mayo de 1990 (RJ 1990, 4498).

${ }^{54}$ STSJ Cataluña de 12 febrero de 2019 (JUR 2019, 95526).
} 
que incida en la génesis de la enfermedad, sino que ha de ser el único factor causal desencadenante de la misma ${ }^{55}$. Por ello, solo se considera accidente de trabajo la enfermedad no profesional cuando de manera fehaciente y sin que dé lugar a duda alguna, se acredite que la causa determinante de la enfermedad se debió a la ejecución de su trabajo ${ }^{56}$. Quedan por tanto fuera del concepto de accidente de trabajo aquellas enfermedades vinculadas causal pero indirecta u ocasionalmente al trabajo, y las caracterizadas por concausalidad o causalidad compleja ${ }^{57}$. En este sentido, no merece la calificación de accidente de trabajo la enfermedad que es fruto de la confluencia de varias causas, alguna de las cuales proviene del trabajo, pero no otras. Se exige que la única causa de la enfermedad sea el trabajo, por lo que no basta con que la patología se desencadene a consecuencia del modo en que el trabajador vivencia determinados avatares de la relación laboral, sino que también se requiere que no confluyan otros elementos desencadenantes ${ }^{58}$. A sensu contrario, sí que tendrá la consideración de accidente de trabajo aquella enfermedad cuya única causa desencadenante tenga origen laboral ${ }^{59}$.

- Inexistencia de causas extralaborales que puedan haber desencadenado la enfermedad. Ante las dificultades de probar que el factor laboral es el único y exclusivo desencadenante de la patología, constituye un elemento de ponderación esencial para su consideración como enfermedad del trabajo la no concurrencia en el supuesto de elementos objetivos que puedan haber desencadenado la psicopatología más allá de los laborales ${ }^{60}$. De este modo, sin presencia de ningún factor extralaboral objetivo que pueda haber desencadenado la patología, un factor laboral, como un conflicto, puede ser entendido como la causa exclusiva de la psicopatología, mereciendo esta la calificación de accidente de trabajo ${ }^{61}$. Por el contrario, la presencia de factores extralaborales con mayor impacto permiten excluir la etiología laboral de la dolencia, descartando la consideración de accidente de trabajo de la enfermedad padecida ${ }^{62}$.

- Relevancia de las psicopatologías previas. La existencia de enfermedades previas de índole psicológica constituye un indicio de que la psicopatología no tiene su causa laboral ${ }^{63}$. Con todo, la existencia de un proceso anterior con sintomatología ansioso-depresiva no excluye automáticamente la naturaleza profesional de la

\footnotetext{
55 STSJ Islas Canarias (Las Palmas) de 26 mayo de 2020 (JUR 2020, 279603)

${ }^{56}$ SSTS de 10 de marzo de 1981 (RJ 1981, 1337) y de 24 de mayo de 1990 (RJ 1990, 4498).

57 SSTSJ Andalucía (Granada) de 9 de marzo de 2019 (JUR 2019, 139727) y de 13 febrero de 2020 (JUR 2020, 187961). Cfr. GONZÁLEZ DE PATTO, R.Ma.. "El síndrome de desgaste personal o de burn out y las técnicas jurídico-laborales de tutela: reflexiones en torno a la sentencia del Juzgado de lo Social núm. 16 de Barcelona de 27 de diciembre de 2002", op. cit., pp. 617 y ss.

58 STSJ Andalucía (Sevilla) de 29 junio de 2017 (JUR 2017, 213024) y STSJ Navarra de 5 de marzo de 2014 (JUR 2014, 118970).

${ }^{59}$ STSJ Galicia de 16 junio de 2020 (JUR 2020, 238200).

${ }^{60}$ STSJ Asturias de 18 noviembre de 2011 (JUR 2011, 426370).

${ }^{61}$ STSJ Cataluña de 27 noviembre de 2013 (JUR 2014, 22959).

${ }^{62}$ STSJ Cataluña de 12 julio de 2007 (AS 2007, 1445).

${ }^{63}$ STSJ Comunidad Valenciana de 13 febrero de 2008 (JUR 2008, 155076).
} 
contingencia posterior, siempre que se acredite que la misma tiene su origen laboral por la materialización de los riesgos psicosociales ${ }^{64}$.

- Las consecuencias dañosas han de ser constatadas en su realidad y gravedad y han de atribuirse exclusivamente al ámbito laboral; y ello, aunque el medio laboral no suponga objetivamente un riesgo para el resto de los trabajadores ${ }^{65}$.

- Para la calificación de una psicopatología como enfermedad del trabajo no resulta preciso que la problemática laboral generadora del trastorno obedezca a incumplimientos del empresario o provenga de actuaciones de este no sujetas a derecho, ya que la razón de la calificación está en la causalidad de la enfermedad por el trabajo, y no en el hecho de que esta se origine por haber soportado en el medio laboral una situación injustificada.

Como contrapunto a la interpretación de la causa exclusiva laboral apuntada, se va abriendo paso tímidamente una línea exegética más flexible, que identifica el concepto de causa exclusiva con el de causa prevalente. De acuerdo con este enfoque, entre enfermedad y trabajo se exige una relación de causalidad directa y fundamental del trabajo en la enfermedad, pero la existencia de otras causas de menor entidad no excluye por sí misma la consideración de accidente de trabajo ${ }^{66}$.

Conforme a esta interpretación, si bien la literalidad del art. 156.2 e) LGSS exige que la causa exclusiva que desencadene la enfermedad sea laboral, "no se puede desconocer la grave dificultad que entraña llegar a tal conclusión en cada caso concreto, atendida la circunstancia de que el trabajador, como cualquier otro ser humano, no vive aisladamente cada problemática y, por lo tanto, resulta extremadamente difícil aislar una sola causa como único y exclusivo detonante de un trastorno mental para valorar su probable origen laboral" 67

Teniendo en cuenta lo anterior, se entiende que la causa exclusivamente laboral exigida por el art. 156.2 e) LGSS ha de considerarse en relación con las psicopatologías de acuerdo con un criterio de prevalencia; es decir:

“(...) valorando como laboral la contingencia si es que la causa principal de la dolencia considerada es laboral, sin necesidad de que no exista ningún otro factor que pueda incidir en su causación. De suerte que, pese a que puedan existir otras posibles causas que interactúen con la de origen laboral e incluso modificar su incidencia -valorándose pues la incidencia conjunta de todos los factores o causas-, habrá de estarse a que la laboral sea la principal o prevalente, o, en otros términos, que ésta por sí misma pueda considerarse de suficiente entidad para ser causa de la patología. Y esto es lo que sucede en el presente caso ya que no se conocen otras causas de origen común con mayor impacto que permitan excluir de forma indubitada el carácter laboral de la dolencia que aqueja a la actora"68.

\footnotetext{
${ }^{64}$ STSJ Asturias de 16 marzo de 2007 (JUR 2007, 214833).

${ }^{65}$ STSJ Aragón de 16 de febrero de 2011 (JUR 2011, 283407).

${ }^{66}$ MARTÍNEZ BARROSO, M ${ }^{\mathrm{a}}$.R., Las enfermedades del trabajo, Valencia, Tirant lo Blanch, 2002, p. 67.

${ }^{67}$ STSJ Comunidad Valenciana de 15 septiembre de 2015 (JUR 2015, 279309) y STSJ Cataluña de 12 julio de 2007 (AS 2007, 1445).

${ }^{68}$ Ibidem.
} 
Desde esta perspectiva hermenéutica se considera que, para que una psicopatología sea calificada como accidente de trabajo, el entorno laboral ha de constituir una condición relevante en la producción del resultado, y sin cuyo concurso no se hubiera producido el efecto lesivo. Evidentemente, se exige una relación de causalidad de la dolencia con el trabajo, pero se interpreta que el medio laboral ha de jugar un papel preferente, importante, prevalente o coadyuvante, aunque no exclusivo ${ }^{69}$.

\section{El burnout como enfermedad del trabajo: especial referencia al personal sanitario}

Como se ha venido apuntado, las enfermedades psicológicas muestran una etiología heterogénea, ofreciendo una diversidad de posibles causas. La determinación de las relaciones de causalidad entre trabajo y lesión es por lo general casuística, y por ello resulta difícil establecer criterios generales sobre supuestos en los que se considera que concurre dicha conexión o aquellos otros en los que se rechaza ${ }^{70}$.

Teniendo presente esta dimensión casuística, que ha de presidir cualquier análisis en la materia, la conexión entre trabajo y psicopatología quedará suficientemente probada si existe una identificación y diagnóstico previo del burnout en el trabajador, al ser esencialmente este síndrome de etiología laboral ${ }^{71}$. Así, las psicopatologías derivadas de burnout, teniendo en cuenta la íntima conexión del síndrome del trabajador quemado con el medio laboral, no plantean a limine problemas para su encuadramiento dentro de las enfermedades del trabajo y, consecuentemente, su calificación como accidentes de trabajo ex art. 156.2 e) LGSS. La propia naturaleza, identidad y definición del burnout apoyan esta tesis $^{72}$.

Sin embargo, la práctica judicial no avala de forma unánime la anterior consideración, pues existen múltiples resoluciones que no reconocen como contingencia profesional al burnout por diferentes motivos; y ello, pese a estar constatada la existencia del síndrome $^{73}$. En este sentido, la exigencia de causa exclusiva que deriva del art. 156.2 e)

\footnotetext{
${ }^{69}$ STSJ Madrid de 31 mayo de 2019 (JUR 2019, 215499).

${ }^{70}$ STSJ Andalucía (Granada) de 13 febrero de 2020 (JUR 2020, 187961).

${ }^{71}$ Apoya esta tesis la doctrina mayoritaria. Por todos, COLLADO GARCÍA, L. "Concepto, calificación jurídica y tipología del acoso moral en el trabajo ("Mobing"): diferencias con otras figuras afines", en AAVV, Riesgos psicosociales y su incidencia en las relaciones laborales y seguridad social, Madrid, Consejo General del Poder Judicial, 2004, p. 75; SÁNCHEZ PÉREZ, J., "El síndrome del trabajador quemado (burn out): su contenido y su polémico encuadramiento jurídico-laboral”, op. cit., pp. 31-50; y GALA DURÁN, C., "El síndrome de «estar quemado» o de agotamiento profesional y su calificación como accidente de trabajo", op. cit., pp. 85-96.

72 STSJ Andalucía (Granada) de 13 febrero de 2020 (JUR 2020, 187961), STSJ Murcia de 24 de mayo de 2004 (AS 2004, 1571), STSJ Asturias de 16 marzo de 2007 (JUR 2007, 214833), STSJ Andalucía (Granada) de 12 diciembre de 2007 (JUR 2008, 364086), STSJ Aragón de 14 septiembre de 2020 (JUR 2020, 307773), STSJ Madrid de 30 junio de 2008 (JUR 2010, 32012), STSJ País Vasco de 2 de noviembre de 1999 (AS 1999, 4212) y STSJ Cataluña de 20 de enero de 2005 (AS 2005, 31).

${ }^{73}$ De hecho, los escasos estudios sobre la materia localizan más resoluciones judiciales que desestiman la consideración de accidente de trabajo del burnout, que aquellas que lo consideran inserto en la categoría de contingencias profesionales. TEJERO ACEVEDO, R., GONZÁLEZ TRIJUEQUE, D. y DELGADO MARINA, S., "El burnout como forma de estrés laboral y su dimensión forense”, op. cit., pp. 56-66.
} 
LGSS ha llevado, en no pocas ocasiones, a desestimar la consideración de accidente de trabajo del burnout diagnosticado cuando este concurre con otras dolencias ${ }^{74}$. Se presentan en este punto los problemas que han sido expuestos con anterioridad en relación con la interpretación que se ha venido realizando por los órganos jurisdiccionales sobre el concepto de causa exclusiva. A ello ha de añadirse que, con relativa frecuencia, los órganos jurisdiccionales evidencian un desconocimiento del burnout, confundiendo el síndrome con otros problemas de etiología psicosocial y, singularmente, con el acoso laboral; extremo este que dificulta, cuando no impide, su valoración como contingencia profesional $^{75}$.

Además, y sin perjuicio de lo anterior, la propia naturaleza multidimensional del síndrome de estar quemado plantea diferentes variables que hacen que no siempre resulte fácil en la práctica identificar una situación de burnout $^{76}$. Es evidente que una vez identificado y acreditado, las psicopatologías que se derivan del síndrome como causa exclusiva tendrán consideración de accidente de trabajo ex art. 156.2 e) LGSS, pero la enorme casuística que se puede presentar en el proceso de delimitación del síndrome hacen necesario examinar algunos elementos que resultan claves a este respecto y que, en relación con el personal sanitario, cabe sintetizar del siguiente modo:

a) Ocupación sanitaria y burnout. El valor indiciario que supone la naturaleza asistencial de la profesión en relación con el burnout, no puede interpretarse en un sentido tan amplio que conduzca necesariamente a entender la concurrencia del síndrome por el mero hecho de alegarlo ocupando una profesión sanitaria, y, por tanto, proclive al síndrome. Como criterio general, los órganos jurisdiccionales han descartado una interpretación amplia del burnout, limitándolo a los supuestos en los que esté probado que existe una clara relación causa-efecto entre el trabajo y la enfermedad del trabajador, sin que la profesión que ocupe el trabajador predetermine la existencia o no de burnout ${ }^{77}$. En este sentido, la mera condición de médico no basta para justificar la existencia de burnout con base en "resultados porcentuales de una serie de estudios cuyo valor científico escapa al conocimiento de este juzgador y que, por tanto, no pueden elevar a la categoría de axioma o hecho notorio (y, por tanto, excusado de probanza) la constatación de que todos los médicos padecen semejante síndrome"78.

b) Dimensión subjetiva: la personalidad del trabajador quemado. Hay características intrínsecas del individuo y circunstancias personales y familiares que pueden hacer que un determinado sujeto sea más o menos vulnerable y propenso a padecer burnout. Así,

\footnotetext{
${ }^{74}$ Por todas, STSJ Cataluña de 30 de marzo de 2010 (JUR 2010, 268428), STSJ Comunidad Valenciana de 15 de enero de 2009 (JUR 2009, 252757), STSJ Andalucía (Sevilla) de 9 de octubre de 2008 (JUR 2009, 146985), STSJ Galicia de 18 de septiembre de 2008 (JUR 2008, 352276) y STSJ País Vasco de 26 de junio de 2007 (JUR 2007, 337162).

75 STSJ Andalucía (Granada) de 10 marzo de 2010 (JUR 2011, 98433).

${ }^{76}$ Cfr. STSJ Madrid de 9 de marzo de 2011 (JUR 2011, 168819), ATS de 3 de marzo de 2011 (JUR 2011, 102217), STSJ Andalucía (Sevilla) de 26 de marzo de 2009 (JUR 2009, 222106) y STSJ Navarra de 9 de noviembre de 2007 (JUR 2009, 164644).

${ }^{77}$ GALA DURÁN, C., "El síndrome de «estar quemado» o de agotamiento profesional y su calificación como accidente de trabajo", op. cit., pp. 85-96. Cfr. STSJ Murcia de 24 de mayo de 2004 (AS 2004, 1571). ${ }^{78}$ STSJ Islas Canarias (Santa Cruz de Tenerife) de 6 de noviembre de 2013 (JUR 2014, 116982).
} 
rasgos de personalidad como el ser perfeccionista, tener un alto nivel de autoexigencia, ser idealista, tener dificultades para gestionar situaciones de estrés o ser muy sensible a las necesidades y demandas de los demás, son características de la personalidad que incrementan la probabilidad de sufrir esta patología. Sin embargo, el que el trabajador tenga características de su personalidad que le hagan proclive al burnout no impide la consideración del síndrome como un accidente de trabajo, en la medida en que no son patológicos en sí mismos, sino que su derivación hacia la enfermedad se produce por la conjunción del elemento laboral ${ }^{79}$. De este modo, las variables de la personalidad del trabajador, siempre que no constituyan una patología en sí mismas ${ }^{80}$, no son determinantes en la calificación como laboral de la contingencia si consta un claro nexo causal entre el trabajo y la psicopatología derivada del burnout ${ }^{81}$.

Resulta ilustrativo el caso de un médico que fue diagnosticado de trastorno adaptativo crónico con sintomatología ansiosa y depresiva y que falleció por infarto. La resolución hace especial referencia a la personalidad perfeccionista y obsesiva del trabajador ${ }^{82}$ : "desde el mismo momento de su llegada al centro de salud, demostró un afán de compromiso, entrega y pasión en su trabajo que destacaba enormemente y que le llevaba a sentir como propios muchos de los problemas que sus pacientes les presentaban, realizando gestiones, visitas institucionales, hospitalarias, a los domicilios de los pacientes, fuera del horario habitual del centro (...). Destaca la gran ilusión puesta en su trabajo y el esfuerzo brutal por realizarlo, desempeñándolo incluso fuera de su jornada laboral, y (...) su personalidad enormemente perfeccionista (...). Durante la vida profesional compartida con él, predominó el sentimiento de angustia, ansiedad y sufrimiento en el desempeño de su trabajo". Sin perjuicio de ello, se entiende que la patología que le llevó a la muerte se desencadenó al desempeñar su actividad profesional, concurriendo el síndrome de burnout. Es por ello, que el infarto es calificado como accidente de trabajo: "debemos concluir que procede la estimación de la demanda (...) de accidente de trabajo, por contingencia de enfermedad diagnosticada síndrome de burnout por la realización de sus actividades profesionales en calidad de médico de atención primaria en Centro de Salud. Significando que el hecho constatado que (...) posea una personalidad perfeccionista y obsesiva, autoexigente y sumamente responsable de dedicación y entrega a sus tareas profesionales, no constituya en sí mismo enfermedad, sino que ha surgido en el Doctor C. al desempeñar su actividad profesional con los pacientes y beneficiarios de la Seguridad Social, cuyas mermas han originado un desgaste anímico determinante (...)".

c) Dimensión objetiva: las condiciones de trabajo y el nivel de estrés. Como se ha expuesto, ciertas personalidades resultan más proclives al burnout que otras. Así,

\footnotetext{
${ }^{79}$ STSJ País Vasco de 2 de noviembre de 1999 (AS 1999, 4212).

${ }^{80}$ STSJ Comunidad Valenciana de 13 febrero de 2008 (JUR 2008, 155076).

${ }^{81}$ STSJ Cataluña de 20 de enero de 2005 (AS 2005, 31). A sensu contrario, cabe rechazar la existencia de accidente de trabajo en aquellas psicopatologías en las que la incapacidad para el trabajo viene fundamentada en una alteración anímica o patología psíquica previa, considerando que los problemas laborales resultan un mero añadido a estos episodios previos incapacitantes. Vid. STSJ Madrid de 11 de septiembre de 2006 (AS 2007, 731).
}

${ }^{82}$ SJS n ${ }^{\circ} 10$ de Sevilla de 22 de abril de 2003 (n 245/2003). 
condiciones de trabajo que para ciertos trabajadores resultan inocuas, para otros, con específicas características personales, pueden desencadenar determinadas psicopatologías. Resulta cuestionable en estas circunstancias hasta qué punto cabe considerar como accidente de trabajo las patologías de un trabajador que, derivadas de burnout, objetivamente no presentan condicionantes organizativos de entidad que incidan en el resto de los trabajadores. En este sentido, cabe diferenciar dos líneas interpretativas.

Un sector jurisprudencial ha mantenido que el hecho de que el trabajo en sí mismo considerado se pueda entender objetivamente como causa insuficiente para desencadenar la enfermedad diagnosticada, porque en cualquier otro trabajador o en un parámetro estándar carecería de los efectos que ha causado en el caso concreto, no puede determinar que se excluya la laboralidad de la contingencia en relación con aquellos trabajadores cuya personalidad de base resulte proclive al síndrome. Y ello, por cuanto una interpretación de ese alcance supondría excluir la laboralidad de la patología en todos aquellos casos en los que el trabajador presentara en sus rasgos de personalidad ciertos caracteres más acusados que el considerado estándar ${ }^{83}$. Así, se ha señalado que no obsta la consideración de accidente de trabajo la psicopatología derivada de burnout por mucho que las condiciones laborales en las que el mismo se desarrolle sean comunes para todos los trabajadores sin que ninguno de ellos hubiere desarrollado ninguna patología, porque "no todas las personas tienen el mismo grado de resistencia psicológica ante las circunstancias adversas que han de afrontar" ${ }^{84}$. Resulta muy gráfica a este respecto la motivación de alguna resolución judicial: “(...) cuando varios trabajadores desempeñen puestos de trabajo con la misma exigencia física durante el mismo o semejante lapso temporal, puede suceder que solo alguno o algunos de ellos desarrollen una enfermedad orgánica derivada de dicho trabajo. Sin necesidad de que un trabajador presente antecedentes patológicos, el sistema osteoarticular difiere entre unas y otras personas, lo que supone que la misma exigencia física puede desencadenar una enfermedad en alguno de ellos y no en los restantes. Pero el hecho de que otros trabajadores que realizan una tarea semejante, no desarrollen esta dolencia, no excluye que si un trabajador sin antecedentes patológicos, como consecuencia de su actividad laboral, desarrolla una dolencia orgánica, deba declararse la existencia de accidente de trabajo por enfermedad no listada. Lo mismo acontece con las patologías psiquiátricas" ${ }^{15}$.

Desde otra línea interpretativa más estricta, se ha mantenido que cualquier calificación de psicopatología derivada de burnout como accidente de trabajo, no solo ha de individualizar la situación del trabajador, sino también evidenciar la dimensión laboral del síndrome y su entidad. Así, la consideración como profesional de la contingencia que deriva del burnout exige la constatación de que, en el caso concreto, el elemento laboral comporta una presión superior a la del desempeño ordinario de cualquier puesto de trabajo remunerado; es decir, que confluyen elementos particulares de alta presión y responsabilidad, conflictividad, exceso de carga de trabajo, asunción de nuevas

\footnotetext{
${ }^{83}$ STSJ Cataluña de 12 de julio de 2006 (AS 2007, 1445).

${ }^{84}$ STSJ Comunidad Valenciana de 15 septiembre de 2015 (JUR 2015, 279309).

${ }^{85}$ STSJ Aragón de 16 de febrero de 2011 (JUR 2011, 283407).
} 
responsabilidades, entre otra serie de condiciones que configuran el clima laboral, y por cuya exposición prolongada se produce la reacción patológica individual de un trabajador en particular ${ }^{86}$. En este sentido, se ha rechazado la consideración de accidente de trabajo de las psicopatologías sufridas por un trabajador por derivar de condicionantes organizativos de concurrencia general en toda la plantilla ${ }^{87}$.

Con base en todo lo anterior, cabría concluir que la calificación del burnout como contingencia profesional requiere de la concurrencia de dos elementos íntimamente ligados: la existencia de situaciones de estrés excepcionales, en un grado y durante un periodo de tiempo superior al habitual en el desempeño del puesto de trabajo, y que estas situaciones sean concretas e individualizables en la persona de cada uno de los trabajadores. En función de la tendencia jurisprudencial que se acoja, lo que dependerá en gran medida de la concreta casuística que se examine, los referidos elementos serán ponderados desde una perspectiva más o menos subjetivista.

\section{A modo de conclusión}

El burnout constituye uno de los riesgos psicosociales de mayor trascendencia en las sociedades occidentales, teniendo en cuenta el modelo socioeconómico y cultural que en las últimas décadas se ha venido conformando. La tendencia expansiva de las tecnologías de la información y comunicación como herramientas de trabajo, la consolidación de la denominada sociedad de la queja, y el peso que las profesiones asistenciales están adquiriendo en nuestro modelo de organización productivo, constituyen elementos clave que dibujan un contexto idóneo para la aparición y desarrollo del síndrome de quemarse en el trabajo. A todo ello, ha de añadirse los efectos que sobre las profesiones asistenciales ha tenido, y está teniendo, la pandemia del covid-19. Pese a que el covid-19, en cuanto a hecho social total, se ha proyectado sobre todos los ámbitos profesionales, la incidencia de la pandemia en el ámbito de los profesionales sanitarios ha sido singularmente relevante.

El síndrome de estar quemado, en su consideración de estrés crónico vinculado al trabajo, tiene múltiples implicaciones en materia de seguridad social, lo que constituye un problema complejo y de indudable trascendencia social ${ }^{88}$. A estos efectos, la consideración del burnout como accidente de trabajo se nos presenta como un elemento esencial sobre el que poder articular un régimen protector, y, por ende, preventivo, frente al síndrome de estar quemado.

Ante la imposibilidad de encuadrar el burnout en el listado de enfermedades profesionales, y teniendo en cuenta la íntima relación del síndrome con el trabajo, los órganos jurisdiccionales han ido asimilando el burnout a un accidente de trabajo por la vía del art. 156.2 e) LGSS. Así, y con base en ese precepto, que considera como accidente

\footnotetext{
${ }^{86}$ STSJ Andalucía (Granada) de 13 de febrero de 2020 (JUR 2020, 187961).

${ }^{87}$ STSJ Cataluña de 1 de diciembre de 2014 (JUR 2015, 39776).

${ }^{88}$ Vid. BORRAJO DACRUZ, E., "El agotamiento profesional como accidente de trabajo", Actualidad Laboral, $\mathrm{n}^{\circ} 7$ (2005), pp. 786 y ss.
} 
de trabajo las enfermedades que, sin ser profesionales, "contraiga el trabajador con motivo de la realización de su trabajo, siempre que se pruebe que la enfermedad tuvo por causa exclusiva la ejecución del mismo", la jurisprudencia ha ido considerando paulatinamente el burnout como un accidente de trabajo.

La calificación del burnout como accidente de trabajo ex art. 156.2 e) LGSS presenta algunas dificultades aplicativas e interpretativas, principalmente en lo que se refiere a la acreditación de la causa exclusiva de la patología en el trabajo, teniendo en cuenta la importancia de las variables moduladoras personales en la dinámica del síndrome. Frente a una jurisprudencia que interpreta de forma estricta el concepto de causa exclusiva, y que actualmente resulta dominante, concurre otra línea exegética más flexible que asimila el concepto de causa exclusiva al de causa prevalente. Esta última interpretación se acomoda de forma más eficaz a la protección de los trastornos de origen psicosocial; trastornos que están llamados a tener un protagonismo indudable en la denominada pospandemia, por los efectos que sobre la salud mental de los trabajadores, especialmente sanitarios, ha conllevado y conllevará la situación vivida por el covid-19.

\section{Bibliografía}

BALDWIN Jr, D.C. y DAUGHERTY, S.R., "Interprofessional conflict and medical errors: results of a national multi-specialty survey of hospital residents in the US", Journal of Interprofessional Care, vol. 22, nº 6 (2008).

BARREIRO GONZÁLEZ, G. (dir.), Las enfermedades del trabajo: nuevos riesgos psicosociales y su valoración en el derecho de la protección social, Madrid, Ministerio de Trabajo y Asuntos Sociales, 2007. Disponible en https://www.diba.cat/documents/467843/69764218/100517.pdf/7e8912f5-f474-40a7a7c9-86fc96abeb10.

BORRAJO DACRUZ, E., "El agotamiento profesional como accidente de trabajo", Actualidad Laboral, $\mathrm{n}^{\circ} 7$ (2005).

BOUZA, E., GIL MONTE, P.R. y PALOMO, E., "Síndrome de quemarse por el trabajo (burnout) en los médicos de España”, Revista Clínica Española, vol. 220, nº 6 (2020).

BUENO FERRÁN, M. y BARRIENTOS-TRIGO, S., "Cuidar al que cuida: el impacto emocional de la epidemia de coronavirus en las enfermeras y otros profesionales de la salud", Enfermería Clínica, vol. 31, nºxtra. 1 (2021).

CAÑADAS-DE LA FUENTE, G.A. y otros, "Evidencia de validez factorial del Maslach Burnout Inventory y estudio de los niveles de burnout en profesionales sanitarios", Revista Latinoamericana de Psicología, vol. 46, n 1 (2014).

CAVAS MARTÍNEZ, F., “Aspectos jurídicos de la enfermedad profesional: estado de la cuestión y propuestas de reforma", Medicina y Seguridad del Trabajo, suplemento extraordinario (2016). 
CHERNISS, C., Professional burnout in human service organizations, Nueva York, Praeger, 1980.

COLLADO GARCÍA, L. "Concepto, calificación jurídica y tipología del acoso moral en el trabajo ("Mobing"): diferencias con otras figuras afines", en AAVV, Riesgos psicosociales y su incidencia en las relaciones laborales y seguridad social, Madrid, Consejo General del Poder Judicial, 2004.

CONTRERAS HERNÁNDEZ, O., "La inclusión de los riesgos psicosociales en el cuadro de enfermedades profesionales: evidencias y propuestas para una revisión legal”, en AAVV, Accidentes de trabajo y enfermedades profesionales. Experiencias y desafíos de una protección social centenaria (I), Murcia, Ediciones Laborum, 2020.

EDELWICH, J. y BRODSKY, A., Burnout: Stages of Disillusionment in the Helping Professions, Nueva York, Human Sciences Press, 1980.

GALA DURÁN, C., "El síndrome de «estar quemado» o de agotamiento profesional y su calificación como accidente de trabajo", La administración práctica, nº 12 (2018).

GARCÍA-IGLESIAS, J.J. y otros, "Impacto del SARS-COV-2 (covid-19) en la salud mental de los profesionales sanitarios: una revisión sistemática", Revista Española de Salud Pública, vol. 94 (2020).

GIL MONTE, P.R., "Cómo evaluar y prevenir el síndrome de quemarse por el trabajo", Gestión Práctica de Riesgos Laborales, no 34 (2007).

GIL MONTE, P.R., El síndrome de quemarse por el trabajo (burnout). Una enfermedad laboral en la sociedad del bienestar, Madrid, Pirámide, $4^{\circ}$ ed., 2015.

GÓMEZ-URQUIZA, J.L. y otros, "Factores de riesgo y niveles de burnout en enfermeras de atención primaria: una revisión sistemática”, Atención Primaria, vol. 49, no 2 (2017).

GONZÁLEZ DE PATTO, R.Ma ., "El síndrome de desgaste personal o de burn out y las técnicas jurídico-laborales de tutela: reflexiones en torno a la sentencia del Juzgado de lo Social núm. 16 de Barcelona de 27 de diciembre de 2002", Actualidad Laboral, no 35 (2003).

GONZÁLEZ ORTEGA, S., "Las enfermedades profesionales: Un concepto de delimitación compleja para un fenómeno social de relevancia", en AAVV, Las enfermedades profesionales, Valencia, Tirant lo Blanch, 2017.

IGARTUA MIRÓ, Ma . T., "La nueva lista de enfermedades profesionales y la inamovilidad respecto de las dolencias derivadas de riesgos psicosociales", Actualidad Laboral, $\mathrm{n}^{\circ} 22$ (2007).

JERNG, J. S. y otros, "Workplace interpersonal conflicts among the healthcare workers: Retrospective exploration from the institutional incident reporting system of a universityaffiliated medical center", PloS One, vol. 12, nº 2 (2017). 
LANZ, J.J. y BRUK-LEE, V., "Resilience as a moderator of the indirect effects of conflict and workload on job outcomes among nurses", Journal of Advanced Nursing, vol. 73, $\mathrm{n}^{\circ}$ 12 (2017).

LEGUA RODRIGO, M ${ }^{\text {a }}$.C., "Concepto legal y concepto doctrinal de enfermedad profesional: interpretación jurisprudencial de la lista de enfermedades profesionales del RD 1299/2006”, Revista de Derecho de la Seguridad Social, nº 20 (2019).

LÓPEZ GANDÍA, J. y AGUDO DÍAZ, J., Nueva regulación de las enfermedades profesionales, Albacete, Bomarzo, 2007.

LOZANO, M.L. y otros, "Descripción de los niveles de Burnout en diferentes colectivos profesionales", Aula Abierta, vol. 36, no 1-2 (2008).

LLANEZA ÁLVAREZ, F.J., La ergonomía forense. Pruebas periciales en prevención de riesgos laborales, Valladolid, Lex Nova, $2^{\mathrm{a}}$ ed., 2007.

MACÍA-RODRÍGUEZ, C. y otros, "Síndrome de burnout en especialistas de medicina interna y factores asociados a su desarrollo", Revista Clínica Española, vol. 220, n 6 (2020).

MARTÍNEZ BARROSO, Ma.R., "La consideración de la actitud pasiva empresarial ante el hostigamiento psicológico como incumplimiento preventivo y recargo de prestaciones en supuestos de laboralidad de mobbing", Relaciones Laborales, $\mathrm{n}^{\mathrm{o}} 11$ (2010).

MARTÍNEZ BARROSO, M ${ }^{\mathrm{a}}$.R., Las enfermedades del trabajo, Valencia, Tirant lo Blanch, 2002.

MARTÍNEZ BARROSO, Mª.R., "Sobre las enfermedades profesionales no listadas (A propósito de un supuesto de síndrome de desgaste personal o de burn-out)", Revista de Derecho Social, no 10 (2000).

MASLACH, C. y JACKSON, S.E., "The Measurement of Experienced Burnout", Journal of Organizational Behavior, vol. 2 (1981).

MONEREO PÉREZ, J.L. y FERNÁNDEZ AVILÉS, J.A., "Determinación de contingencias de la Seguridad Social”, Aranzadi Social, no 19 (2019).

MORENO-JIMÉNEZ J.E. y otros, "The Job Demands and Resources Related to COVID19 in Predicting Emotional Exhaustion and Secondary Traumatic Stress Among Health Professionals in Spain", Frontiers in Psychology, nº 12 (2021).

ORTELLS ABUYÉ, N. y otros, “Caracterización de las agresiones producidas al personal sanitario del servicio de urgencias en un hospital comarcal”, Enfermería Global, vol. 12, $\mathrm{n}^{\mathrm{o}} 30$ (2013).

POQUET CATALÁ, R., "El sistema de calificación de enfermedades profesionales y la posible inclusión de nuevas profesiones", Trabajo y Derecho, nº 39 (2018).

RODRÍGUEZ ESCANCIANO, S., "Los riesgos psicosociales en el teletrabajo a domicilio bajo las coordenadas de la nueva economía «low touch»", en AAVV, 
Accidentes de trabajo y enfermedades profesionales. Experiencias y desafios de una protección social centenaria (II), Murcia, Ediciones Laborum, 2020.

ROJAS RIVERO, G.P., "Los llamados riesgos emergentes de carácter psicosocial vinculados al trabajo", en AAVV, Accidentes de trabajo y enfermedades profesionales. Experiencias y desafíos de una protección social centenaria (II), Murcia, Ediciones Laborum, 2020.

SÁNCHEZ PÉREZ, J., "El síndrome del trabajador quemado (burn out): su contenido y su polémico encuadramiento jurídico-laboral", Revista de Información Laboral, $\mathrm{n}^{\circ} 5$ (2016).

SÁNCHEZ PÉREZ, J., La configuración jurídica del accidente de trabajo, Murcia, Ediciones Laborum, 2011.

SERRANO VICENTE, M.I. y otros, "Agresiones a profesionales del sector sanitario en España, revisión sistemática”, Revista Española de Salud Pública, vol. 93 (2019).

TEJERO ACEVEDO, R., GONZÁLEZ TRIJUEQUE, D. y DELGADO MARINA, S., "El burnout como forma de estrés laboral y su dimensión forense", Revista Cubana de Salud y Trabajo, vol. 14, nº 1 (2013).

URRUTIKOETXEA BARRUTIA, M., "Suicidio y accidente de trabajo", Revista de Derecho Social, $\mathrm{n}^{\circ} 41$ (2008).

VALLEJO DACOSTA, R., Riesgos psico-sociales: prevención, reparación y tutela sancionadora, Cizur Menor, Aranzadi, 2005. 